\title{
Lip Prints - An Identification Aid
}

\section{Karki RK}

\begin{abstract}
Department of Forensic Medicine and Toxicology
Dhulikhel Hospital, Kathmandu University Hospital

Kathmandu University School of Medical Sciences, Kavre, Nepal.
\end{abstract}

\section{Corresponding Author}

Raj Kumar Karki

Department of Forensic Medicine and Toxicology

Kathamndu University School of Medical Sciences

Dhulikhel Hospital, Kavre, Nepal

E-Mail: rkkarki17@hotmail.com

Citation

Karki RK. Lip Prints - an Identification Aid. Kathmandu Univ Med J 2012;38(2):55-57.

\section{ABSTRACT}

\section{Background}

Lip prints are the normal lines and furrows in the form of wrinkles and grooves present in the human lip between the inner labial mucosa and outer skin having certain individual characteristics like fingerprints.

\section{Objective}

The aim of the study was to highlight the importance of lip prints in sex determination related to forensic investigation for identification.

\section{Methods}

Study was conducted on 150 medical students which include 75 males and 75 females of Kathmandu University School of Medical Sciences, Dhulikhel, Kavre on 2011. Lip prints were collected and analyzed as per Suzuki's classification.

\section{Results}

There was significant difference between male and female lip print patterns. Type II was most common combining both. Type I and I' was more common in male where as Type I was rare in female. Type II in fourth quadrant was seen in almost all female and also the commonest. Similar patterns in all four quadrants were common findings in female.

\section{Conclusion}

The study showed that each lip print is unique and the sex of the person can be predicted on the basis of patterns present in prints.

\section{KEY WORDS}

Identification, lip prints, sex

\section{INTRODUCTION}

According to Locard's Exchange principle when two objects come into contact, there is always a transfer of material from each other. Traces from the scene may be carried away on the person and at the same time may be left at the scene. ${ }^{1}$ Lip print is one of the evidence that can be left in the crime scene by which it helps in identification purpose. Lip prints are the normal lines and furrows in the form of wrinkles and grooves present in the human lip having certain individual characteristics like fingerprints. During investigation it can be found over wine glass, love letters, on private parts etc. ${ }^{2}$ Study of lip prints is known as Cheiloscopy. It is unaltered from six week of intrauterine life till death. It can be visible seen with naked eyes like with lipstick and latent prints are not visible with naked eyes.
Fischer in 1902, first describe the furrows on the red part of the human lips. ${ }^{3}$ However, it was only in 1932, Edmond Locard, recommended the use of lip prints in personal identification. ${ }^{4}$ Synder in 1950 reported that the lip prints are individually distinctive as finger prints. ${ }^{5}$ Suzuki, in 1967, made detailed investigations of the measurement of the lips, the use and colour of rouge, and the method for its extraction to obtain useful data for forensic application. It is thought that hereditary factors may have some influence on the lip print patterns. In 1970, he recalled the attention of everyone on the fact that the possible use of lip prints in personal identification where he examined 107 Japanese females aged $20-36$ years and classified the lip prints into five types. ${ }^{6}$ Mc Donell in 1972 conducted a study on two identical twins and reported that it is indistinguishable 
by every other means but their lip prints were different. ${ }^{4}$ The aim of the study was to highlight the importance of lip prints in sex determination related to forensic investigation for identification.

\section{METHODS}

Study was conducted on 150 medical students which include 75 males and 75 females of Kathmandu University School of Medical Sciences, Dhulikhel, Kavre on 2011. Lip prints were collected and analysis was done as per Suzuki's classification. All individuals were aged between 18 and 25 years. Lips free from any pathology, having absolutely normal transition zone between the mucosa and skin were included in the study. Consent of all the individuals was obtained. The lips of the individuals were cleaned and the brown or red colored lipstick was applied. In white papers fixed on cardboard, the subjects were asked to press his/ her lips onto the papers, so as to leave the clear impression of their lips on the papers. While studying the various types of lip prints, each individual's lips were divided into four compartments, i.e., two compartments on each lip, and were allotted the digits one to four in a clock-wise sequence starting from the subject's upper right. In order to classify the lip prints, the classification proposed by Suzuki and Tsuchihashi was used. Type I - Complete vertical, Type $I^{\prime}$ - Incomplete vertical pattern, Type II- Branching or ' $Y$ ' pattern, Type III- Criss-cross pattern, Type IV- Reticular pattern and Type $\mathrm{V}$ - all other patterns. ${ }^{6}$ The data entry and statistical analysis was done using Microsoft Excel 2010 in statistical package for social sciences (SPSS) version 14 for windows.
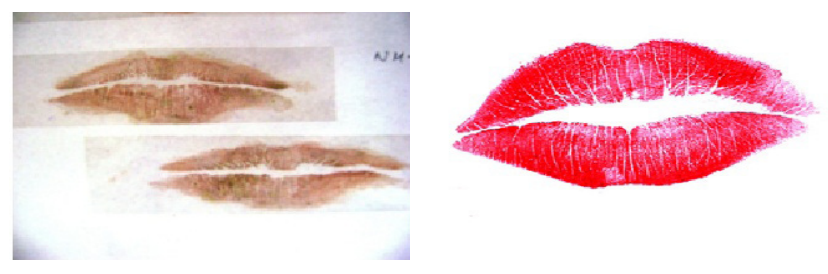

Figure 1. Lip prints

\section{RESULTS}

In overall study, no individual had single type of lip print in all the four compartments and no two or more individuals had similar type of lip print pattern. When the overall pattern was evaluated among all the lip compartments, it was found that Type II (branching) was most common pattern as a whole constituting 59 cases (39.5\%) in which 27 male (35.5\%) and 32 female (42.5\%). However, the least common was the Type $\mathrm{V}$ (reticular) pattern constituting 21 cases $(14 \%)$ in which 8 male $(10.0 \%)$ and 13 female (16.5\%).

Among males, Type I and Type I' was more common constituting 29 cases (38\%) and Type I (complete vertical) is the predominant pattern in all quadrants. Type $\mathrm{V}$ (reticular) pattern is rare in males.

Among females, Type II (branching) pattern was more common constituting 32 cases $(42.5 \%)$ and it was found that Type II in fourth quadrant is seen in almost all females. Similar patterns in all four quadrants are common findings in females. Type I (complete vertical) is rare.

\section{DISCUSSION}

Lip prints are very useful in forensic investigation and personal identification. Personal identification is necessary for unknown deceased person in homicide, suicide, accident, mass disaster, etc. and for living individual who are missing or culprits hiding their identity. They are considered to be one of the most important forms of transfer evidence, and are analogous to finger prints. Lip prints are usually left at crime scenes and can provide a direct link to the suspect. In recent years, lipsticks have been developed that do not leave any visible trace after contact with surfaces such as glass, clothing or cigarette. These lip prints are characterized by their permanence and are, therefore referred to as persistent lip prints. Although invisible, these prints can be lifted using materials as aluminum powder and magnetic powder.

While cheiloscopy - the scientific study of lip prints has captured the imagination of many detectives, it remains a forensic work in progress in need of standardized methodologies to systematize the collection and categorization of the uniquely patterned grooves, furrows, and wrinkles that comprise a human lip print. Research studies and information regarding the use of lip prints as evidence in personal identification and criminal investigation in forensic is very much scanty. In spite of few studies available, the study of Tsuchihashi gives a standard classification of his own for different types of lip prints. ${ }^{7}$ Keeping this classification as the basis, the current study was conducted to study the lip prints of different individuals in different parts of the lips, to establish facts so as to aid in giving further details of lip prints. In our study, it was found that among males Type I and females Type II was common lip print pattern while the least common was the type $V$ pattern. These findings coincide with other studies also. Vahanwalla and Parekh in $\mathbf{2 0 0 0}$ on their study in Mumbai, reported that Type I was dominant and males tented to have different patterns in all quadrants and that females tented to have same pattern in all quadrants. ${ }^{8}$ Manipady, In 2002 studied Indian and Chinese population and found that Type II was the highest incidence among the Indian as well as Chinese. ${ }^{9}$ In Japan, one study showed no lip print showed the same pattern in the investigation of 1364 Japanese subject from 30 to 60 years old. Lip prints of same individual were investigated every month for three years to see whether the lip prints are permanent or not and it showed no change throughout the period. Even in uniovular twins, they were not identical. ${ }^{10}$ Also in 2005, a cadaveric study done by Utsuno et al.concluded that, even after fixation, a satisfactory identification rate could be achieved from examination of the lip prints. ${ }^{11}$ For the 
purpose of determination of sex of the person from lip prints, Gondivkar SM et al in 2009 have studied 70 each male and female subjects in Maharashtra and were able to predict the sex with high degree of accuracy. ${ }^{9}$ Recently in 2010, El Domiaty et al. achieved a detailed cheiloscopic study of the lip-print patterns in Saudi males and females and proved the individuality of lip prints as no identically similar lip-print patterns appeared in two subjects. They reported that even when two subjects exhibited the same type of groove in the same area of the lip, there was specificity in the site and pattern of groove branching or reticulation. ${ }^{12}$

One common problem that is encountered during the cheiloscopic studies is that of smudging or spoiling of lip prints leading to unidentifiable marks. In our study, $8.5 \%$ of all the lip prints were spoiled, the maximum being in the first and second compartments of the males. The reason for this can be attributed to the presence of prominent facial hair among men.

Practical Applications: Suzuki and Tsuchihashi reported two cases where lip prints have proven useful in identification of the criminal. In first case while the lip prints were identified on an envelope and with those of the suspects, the second case lip prints were noted on the undergarments and were studied with the help of color test

\section{REFERENCES}

1. Reddy KSN. The essential of Forensic Medicine and Toxicology: In: Forensic Science Laboratory. 30th ed. India: K. Sugana Devi; 2011.

2. Dikshit PC. Textbook of Forensic Medicine and Toxicolog. In: Identification. 1st ed. New Delhi: Peepee Publishers; 2007.

3. Kasprazak J. Possibilities of cheiloscopy. Forensic Sci Int .1990; 46: 145-51.

4. Aggarwal A. The importance of lip prints (Forensic Files). 24th Oct 2008. Available from: http://lifeloom.com//II2Aggarwal.htm.

5. Synder LM. Textbook of Homicide investigation. In: Identification of dead bodies. 2nd ed. London: Quintessence Publishing; 1950.

6. Suzuki K, Suzuki H, Tsuchihashi Y. On the female lips and rouge. Jpn J Leg Med .1967; 67: 471.

7. Suzuki K, Tsuchihashi Y. A new attempt of personal identification by means of lip print. J Indian Dent Assoc .1970; 42: 8-9. and ultraviolet rays. ${ }^{13}$ In 1987, Federal Bureau Investigation had successfully identified a male bank robber who used female disguises including lipstick. The Federal Bureau Investigation submitted the photographs and lifts of the lip prints that robber had left on the glass door while robbing a bank, which were identified to match with that of suspected robber. These cases suggest that lip print study can definitely be used for criminal identification. ${ }^{14}$ It has been proved beyond doubt that lip prints are as good as finger prints in criminal identification and can be definitely used when no other means of traditional methods of identification are available. However, as far as the legal matters are concerned, this technique needs to be used more frequently in routine civil and criminal litigations.

\section{CONCLUSION}

In overall study, lip prints remain as a constant anatomical structure in all times and are unique to an individual. However it must not be thought at this stage that lip prints are as good in identification as fingerprints. They can only be used when no other traditional methods of identification are available. This could be done by either comparing lip print in total or compartment wise. Lip prints thus hold potential promise as supplementary tools for identification purpose.
8. Vahanwalla SP, Parekh BK. Study on Lip Prints as an Aid to Forensic Methodology. J Forensic Med and Toxicol. 2002; 17(1): 12-18.

9. Verghese AJ,Somasekar M,Babu RU. A study on Lip Print types among the people of Kerala. J Indian Acad Forensic Med. 2010; 32(1): 6-7.

10. Anonymous. Studies on Personal Identification by means of lip prints. Forensic science.1974; $3: 233-248$.

11. Utsuno H, Kanoh T, Tadokoro O, Inoue K. Preliminary study of postmortem identification using lip prints. Forensic Sci Int. 2005; 149: 129-132.

12. El Domiaty. Morphological patterns of lip prints in Saudi Arabia at Almadinah Almonawarah provenance. Forensic Sci Int. 2010; 200: 179.

13. Suzuki K, Tsuchihashi Y. Two criminal cases of lip print. ACTA Criminal Jpn .1975; 41: 61-64.

14. William TR. Lip prints: Another means of identification. J Forensic Dent 1991; 41:190-194. 